\title{
SOUND + VISION: Experimenting with the Anthropological Research Article of the Future
}

\section{DOMINIC BOYER}

(D) http: / / orcid.org/0000-0001-8944-406X

JAMES FAUBION

(D) http:/ / orcid.org/0000-0003-0847-3008

CYMENE HOWE

(D) http:/ / orcid.org/0000-0002-9361-3812

MARCEL LAFLAMME

(D) http: / / orcid.org/0000-0002-7489-4233

Rice University

Are we satisfied with the conventional media for anthropological research and publication?

The question is obviously not a new one. Even before anthropological research and scholarship had consolidated its modern standards of fieldwork, theory, and ethnography in the first decades of the twentieth century, anthropological writing was already part of an ecology of recordings and representations of other ways of being human that ranged from colonial propaganda to exotic-pornographic photography to early filmic and acoustic experiments in salvage ethnography. All absorbed and reproduced the politics of race and empire around them, just as early anthropological writing did. Films like Edward Curtis's In the Land of the Head Hunters (1914) and Robert Flaherty's Nanook of the North (1922) offered, despite their myriad flaws, early glimpses of the potentialities of ethnographic film and indigenous media (see Ginsburg 2002). By the 1930s and 1940s we find larger-scale projects of documentation and salvage - the Library of Congress's Archive of American Folk Song, for example — but also early experiments in using 
film to document visual movement and to compare it across cultures-for example, Gregory Bateson and Margaret Mead's Bathing Babies in Three Cultures (1941) (Jacknis 1988). The 1950s and 1960s saw an explosion of ethnographic filmmaking — we think of figures like Timothy Asch, Robert Gardner, and Jean Rouch, among many others - as well as growing acceptance of film as a medium of anthropological research. By the late 1960s and early 1970s, a new subfield called "visual anthropology" began consolidating (e.g., Collier 1967; Ruby 1975), seeking not only to take the artifacts of multimedia ethnography seriously as vehicles of anthropological theorization and commentary but also to catalyze new experiments in representational method and indigenous-settler collaboration (e.g., Worth and Adair 1970).

Despite this long and complex history of multimedia experimentation in anthropological research practice, it remains fair to say that print has been the mainstream medium of choice for publicizing and communicating anthropological knowledge in the discipline's history to date. It is thus striking but perhaps not surprising that even two decades into the Internet revolution, a typical anthropological article or book looks much as it might have a century ago, even when it is downloaded as an electronic file onto a laptop or a smartphone. What we encounter is a lot of printed text offset by the occasional photograph, still usually in black and white to maximize contrast and print quality for paper publication. The recent and welcome proliferation of online anthropology publications - journals such as Limn, HAU, and Medicine, Anthropology, Theory, to name a few-while doing amazingly innovative work at the level of content, have (as Cultural Anthropology has up until this point) largely composed articles in the formal traditions of the print era. Elsewhere in the human sciences, we have recently seen a few more aggressive efforts to set new multimodal standards for scholarly publication; the pioneering journal Vectors is perhaps the most ambitious and successful example (see McPherson, Anderson, and Kelly n.d.). We find it interesting that despite the abundance of filmic, photographic, and sonic material that most anthropologists now generate in the course of fieldwork, we have not yet really committed ourselves as a discipline to exploring new multimodal forms of anthropological research publication. To be clear, there is a bright and vibrant edge to anthropological research expression these days - think, for example, of the many multimedia and installation projects at the juncture of art and anthropology undertaken by the Ethnographic Terminalia collective. Yet those projects of research expression have not always translated well into the world of research publication, which 
has undeniably depressed their value in terms of mainstream standards - we are not justifying them — of disciplinary research activity.

What Cultural Anthropology aspires to do with our new Sound + Vision section is to develop prototypes for a multimodal future. We wish to work together with authors to ask and answer questions such as: What should the anthropological research article of the future look and sound and feel like? What features and affordances should it offer? What role should embedded video and moving images play? What would be gained by incorporating audio clips or soundtracks? Is it too early to think about syncing an article with a 3D printer in order to materialize objects that would otherwise be described in ethnographic narrative? We are committed to open-mindedness in this inquiry and, as editors and producers of this journal, we are trying to bracket any preconceived notions of how these projects will be realized. At the same time, we are aiming to create an epistemic infrastructure rather than a series of one-offs; that is, we know that reinventing the platform for each individual article is not tenable in terms of time, labor, and expense. Our objective is, instead, to develop an adaptable, modular infrastructure that will, nonetheless, be transformative. It is not just a question of adding more features because it is possible to do, but rather of finding new ways to capture and mobilize the unique intimacy and multisensory character of anthropological research.

In that spirit, we imagine Sound + Vision creating a growing repertoire of tools and toys that will inspire others to rethink how they might design, actualize, and disseminate their work. We expect that Sound + Vision articles may attract new audiences, since today's Cultural Anthropology is not only an open-access journal but also a journal whose principal publication portal is its website. We want to utilize our departure from paper publishing as an opportunity to rethink where this journal might go next. And we want to explore the possibility of finding audiences that are interested in anthropological knowledge, but perhaps not in its traditional container of the eight- to ten-thousand-word, text-dominant research article. We have taken small steps in this direction by juxtaposing sound and video recordings with text in our editor-reviewed Hot Spots and Theorizing the Contemporary web series (see, especially, Howe and Pandian 2016). But Sound + Vision articles will be fully peer-reviewed and they will push beyond the features and affordances already offered in blog-style publications - such as embedded YouTube clips - and toward multimedia formats that strive to ensure the longevity of scholarly materials and yet also fulfill the desire for innovative agility. In other words, we seek a better balance between permanence and flow. 
It was clear to us from the start that Sound + Vision would need to be a collaborative undertaking. Building on the journal's existing partnerships with academic libraries (see Mangiafico and Smith 2014), we reached out to Indiana University, home of the largest university-based ethnographic sound archive in the United States. We struck an agreement whereby the journal would deposit the multimedia content that appears in Sound + Vision articles in the digital collections of the Indiana University Libraries, and we indicated our desire to become the first academic journal to integrate Avalon Media System, an open-source media management tool developed at Indiana and Northwestern Universities, into our production process. For this first iteration of Sound + Vision, we are relying on Avalon's existing functionality (and supplementing it, here and there, with creative workarounds for some of its current limitations). However, thanks to a generous grant from the American Anthropological Association's Committee on the Future of Print and Electronic Publishing, the journal is supporting further development of Avalon's media player so that future iterations of Sound + Vision will be able to incorporate even more advanced technical capabilities.

Producing downloadable versions of Sound + Vision articles came with its own learning curve. Embedding audio and video content in PDF files turns out to be no simple matter; different PDF viewers and devices display media content in different ways, and so we were faced with the prospect of producing files that would function properly for some of our readers and not others. Instead, our PDFs will link out to media content that plays back in a separate browser window: a tradeoff that sacrifices seamless user experience for greater interoperability. We are also making Sound + Vision articles available for download in EPUB format, a specification that was developed for electronic book publishing but that is beginning to see greater adoption by scholarly journals (Carpenter 2013). Our EPUBs will feature embedded media content, which makes for large files that take more time to download but that are (for the most part) device-agnostic and that will play back even in the absence of an Internet connection. It remains to be seen if there is a demand for the EPUB format among our readership, but we encourage readers to try it out and to share your feedback with us. It is only in the process of trying new things and being willing to fail that we can build the kind of publishing infrastructure to which we aspire.

One final word: in the time between the initial announcement of this new section (Boyer, Faubion, and Howe 2015) and today, the world has lost the artist David Bowie, whose formulation "sound and vision" we borrowed in deliberate and respectful recognition of a long history of bold, restless, and virtuosic ex- 
perimentation within and across media. In honor of Bowie, then, this is our modest effort to make anthropological publication an even more reflexive and creative space than it already is. Sound + Vision is just a down payment on our discipline's longstanding dream of multiplying the forms and features of anthropological communication.

\section{REFERENCES}

Boyer, Dominic, James Faubion, and Cymene Howe

2015 “Editors' Introduction to 30.1: Circles Not Pyramids." Cultural Anthropology 30, no. 1: 1-5. http://dx.doi.org/10.14506/ca30.1.01.

\section{Carpenter, Todd A.}

2013 "Is it Time for Scholarly Journal Publishers to Begin Distributing Articles Using EPUB 3?" Scholarly Kitchen, March 19. https://scholarlykitchen.sspnet.org/ 2013/03/19/is-it-time-for-scholarly-journal-publishers-to-begin-distributing-

Collier, Jr., John articles-using-epub-3.

1967 Visual Anthropology: Photography as a Research Method. New York: Holt, Rinehart, and Winston.

Ginsburg, Faye D.

2002 "Screen Memories: Resignifying the Traditional in Indigenous Media." In Media Worlds: Anthropology on New Terrain, edited by Faye D. Ginsburg, Lila AbuLughod, and Brian Larkin, 39-57. Berkeley: University of California Press.

Howe, Cymene, and Anand Pandian, eds.

2016 "Lexicon for an Anthropocene Yet Unseen." Theorizing the Contemporary series, Cultural Anthropology website, January 22. https://culanth.org/fieldsights/803lexicon-for-an-anthropocene-yet-unseen.

Jacknis, Ira

1988 "Margaret Mead and Gregory Bateson in Bali: Their Use of Photography and Film." Cultural Anthropology 3, no. 2: 160-77. http://dx.doi.org/10.1525/ can.1988.3.2.02a00030.

Mangiafico, Paolo, and Kevin Smith

2014 "Reason, Risk, and Reward: Models for Libraries and Other Stakeholders in an Evolving Scholarly Publishing Ecosystem.” Cultural Anthropology 29, no. 2: 21635. http://dx.doi.org/10.14506/ca29.2.03.

McPherson, Tara, Steve Anderson, and Raegan Kelly

n.d. "Editorial Statement." Vectors: Journal of Culture and Technology in a Dynamic Vernacular. http://vectorsjournal.org/journal/index.php?page=EditorialStatement.

Ruby, Jay

1975 "Is an Ethnographic Film a Filmic Ethnography?" Studies in the Anthropology of Visual Communication 2, no. 2: 104-11.

Worth, Sol, and John Adair

1970 “Navajo Filmmakers." American Anthropologist 72, no. 1: 9-34. http://dx.doi. org/10.1525/aa.1970.72.1.02a00050. 